\title{
Breast cancer - extracapsular extension in the sentinel lymph node
}

\author{
Piotr Kędzierawski \\ Department of Radiotherapy, the Holycross Cancer Centre, Institute of the Health Sciences, Collegium Medicum, \\ Jan Kochanowski University, Kielce, Poland
}

Invasive breast cancer is the most common malignancy in women. At present, in the majority of cases it is recognized at an early stage. Its most common site of metastasis is the axilla region, and for women without clinically suspected lymph nodes a sentinel lymph node biopsy (SLNB) is the method of choice in diagnostics and treatment process. It allows, in many cases, axillary lymphadenectomy to be avoided and the risk of complications after a surgical treatment to be diminished. Extracapsular extension (ECE) of nodal metastasis, defined as extension of cancer cells through the nodal capsule, is an important prognostic factor. The aim of this paper is to review the literature on ECE in the sentinel lymph node (SLN).

Key words: breast cancer, sentinel lymph node, extracapsular extension

\section{Introduction}

For the last decade, axillary lymphadenectomy (ALND) has not been mandatory for patients with 1-2 sentinel nodes with macrometastases who were undergoing lumpectomy and adjuvant radiotherapy as part of their treatment, according to an ACOSOG Z0011 trial or an AMAROS trial. The outcomes of these trials showed no differences in recurrence and survival between patients who had undergone ALND and those who had not undergone ALND, but the presence or absence of extracapsular extension was not analyzed in these trials [1-3].

ECE can be connected with poor prognosis and its diameter should be determined, because in many cases this factor determines the necessity of performing an ALND or regional lymph node radiotherapy.

\section{Biological subtype of breast cancer and positive SLN}

Luminal tumours are the most common breast cancer and they represent about $70 \%$ of all cases of breast cancer [4-7]. In most patients with Luminal A cancer, surgery is used up-front.
In women with clinically negative lymph nodes, SLNB is the method of choice instead of an ALND. Some authors point to different factors influencing the presence of metastases in the sentinel lymph nodes, such as: age, the diameter of the tumour, grade, and the lobular type of the cancer. Luminal A breast cancers are usually of low histological grade with slow growth and a good prognosis, however quite frequently, the illness is more advanced at the moment of diagnosis [8-9]. For women with Luminal B HER2 negative cancer, an additionally high Ki-67 factor is connected with the possibility of a positive sentinel lymph node [10-11].

For triple negative or HER2 positive cancer patients, the strategy of treatment has changed lately and therapy usually starts with chemotherapy [12]. For patients with an overexpression of the HER2 receptor, the probability of metastasis to SLN and ECE is much higher [11]. Systemic treatment leads, in more than $40 \%$ of patients, to a complete pathological response (ypTONO) and very often SLNB is advised. However, for women with clinically suspected or with metastasis diagnosed before treatment an ALND is mandatory. On the other hand, for triple

\section{How to cite:}

Kędzierawski P. Breast cancer - extracapsular extension in the sentinel lymph node. NOWOTWORY J Oncol 2020; 70: $203-205$. 
negative or HER2 positive T1 patients, with tumours less than $1 \mathrm{~cm}$ in diameter, surgery is an up-front strategy [12-16].

\section{ECE in a sentinel lymph node and correlation with non-sentinel lymph node (NSLN) metastases}

In most of the papers presented, ECE in sentinel lymph nodes is connected with metastases to NSLNs. More metastatic SLNs are connected with a higher probability of positive NSLNs. The ratio between metastatic sentinel lymph nodes and removed sentinel lymph nodes is very important. The higher the ratio, the greater the probability of metastases to NSLNs [17-21]. In his paper, Palamba showed that for patients with ECE the probability of the occupation of additional lymph nodes by cancer cells is much higher $-84.6 \%$ for massive, $58.5 \%$ for minimal, and only $14.5 \%$ for sentinel lymph nodes without extracapsular extension [22]. Similar conclusions were presented by Gooch et al. The risk of metastases to NSLNs was connected with the diameter of ECE. For infiltration greater than $2 \mathrm{~mm}$, or for lesser than $2 \mathrm{~mm}$, or for no extracapsular infiltration, the probability of the occupation of more than four axillary lymph nodes was 33\%, $8.5 \%$ and $2.5 \%$, respectively [10]. In yet another paper, this feature was also presented, but it was not an independent factor for disease free survival (DFS) and overall survival (OS) [23]. Schwentner, analyzing the outcomes of 324 women showed that the probability of increasing pN status ( $\mathrm{pN} 1$ to $\mathrm{pN2}$-3) was much higher in patients with ECE after performing an axillary dissection [24].

\section{The diameter of ECE in the sentinel lymph node}

In the literature, we do not meet a correct definition of extracapsular extension in connection with its clinical meaning. In pathological reports, however, very often, we find only the sentence that ECE is present and in some that ECE is absent which can be understood as the true absence of ECE or as the situation that this feature was not assessed by the pathologist. In the analysis presented by Vane et al., in a group of 3502 patients, information on ECE was available for about $60 \%$ of them [10]. Nottegar et al. have performed an analysis of proper papers concerning the issue of ECE, and five articles were included by them in their meta-analysis. In four out of the five articles, the analysis was connected only with a short piece of information that ECE was present or absent without estimation of its diameter [25]. The lack of information on the diameter of the ECE can be accepted in a situation where an axillary dissection was performed and there is a huge number of metastatic lymph nodes, which is connected with poorer prognosis and the necessity of systemic treatment, not only for cancers with worse prognosis (triple negative or non-luminal) but also for patients with luminal ones. After SLNB and the presence of ECE, it is mandatory to estimate the diameter of the ECE, because not only is it connected with prognosis, but it also influences the planning of further therapy. The relevance for prognosis of extracapsular extension was proven in patients with other cancers [26-28].

In the $5^{\text {th }}$ edition of The American Joint Committee of Cancer (AJCC) Cancer Staging Manual, the presence of ECE was recognised and named as subcategory pN1biii, but was removed from following editions [29]. This factor has also not been assessed in clinical trials. In the ACOSOG Z0011 trial, patients with ECE were excluded from the analysis and in the AMAROS trial this factor has not been evaluated. The authors pointed to the fact that the diameter of the ECE can influence both DFS and OS. When this diameter exceeded $2 \mathrm{~mm}$, the risk of locoregional failure was greater than $20 \%$ and influenced DFS [30-32]. Nevertheless, this fact was not confirmed by others. In their paper Choi et al. presented the fact that in cases of ECE less than $2 \mathrm{~mm}$ the risk of recurrence was the same as for patients without ECE [33].

Similar conclusions were shown by Barrio et al. However, the mean time of observation was only 21 months, there were no nodal failures in patients with ECE in sentinel lymph nodes and they were not treated with an axillary dissection, but rather biologically oriented systemic treatment and locoregional radiotherapy were used. The risk of nodal failure in this group was only $1.5 \%$ [34]. The research of Kanyilmaz et al. has shown that the extent of the ECE is a prognostic factor for survival in pT1-2N1 breast cancer patients with a diameter of extracapsular extension greater than $1 \mathrm{~mm}$. This factor, according to the authors, was connected with shorter OS and DFS [35].

\section{Conclusions}

In an era of diminishing surgical treatment in the breast area and axilla region, it seems to be very important to precisely estimate the diameter of any extracapsular extension in the sentinel lymph nodes. In an era of biologically directed systemic treatment and conformal radiotherapy, it is probable that we can avoid the harmful consequences of surgical procedures in many patients [12].

Pathologists should include the diameter of the ECE in their reports to help, much more so than presently, clinicians take decisions about the best oncological treatment for women with breast cancer. As the data mentioned shows, a diameter of 1-2 mm for an extracapsular extension in SLN is crucial (pivotal). The prognostic importance of ECE must also be confirmed by future clinical trials.

\section{Conflict of interest: none declared}

\section{Piotr Kędzierawski}

Jan Kochanowski University

Institute of the Health Sciences, Collegium Medicum

Department of Radiotherapy, the Holycross Cancer Centre

ul. Artwińskiego 3

25-734 Kielce, Poland

e-mail: piotrkedzierawski@wp.pl 
Received: 23 Apr 2020

Accepted: 20 May 2020

\section{References}

1. Giuliano AE, Ballman KV, McCall L, et al. Axillary dissection vs no axillary dissection in women with invasive breast cancer and sentinel node metastasis: a randomized clinical trial. JAMA. 2011; 305(6): 569-575, doi: 10.1001/jama.2011.90, indexed in Pubmed: 21304082.

2. Giuliano $\mathrm{AE}$, Ballman $\mathrm{K}, \mathrm{McC}$ all $\mathrm{L}$, et al. Locoregional recurrence after sentinel lymph node dissection with or without axillary dissection in patients with sentinel lymph node metastases: the American College of Surgeons Oncology Group Z0011 randomized trial. Ann Surg. 2010; 252(3): 426-32; discussion 432, doi: 10.1097/SLA.0b013e3181f08f32, indexed in Pubmed: 20739842

3. Rutgers $E$, Donker M, Straver M, et al. Radiotherapy or surgery of the axilla after a positive sentinel node in breast cancer patients: Final analysis of the EORTC AMAROS trial (10981/22023). J Clin Oncol. 2013; 31(18_suppl): LBA1001-LBA1001, doi: 10.1200/jco.2013.31.18_suppl. lba1001.

4. Voduc KD, Cheang MCU, Tyldesley S, et al. Breast cancer subtypes and the risk of local and regional relapse. J Clin Oncol. 2010; 28(10): 16841691, doi: 10.1200/JCO.2009.24.9284, indexed in Pubmed: 20194857.

5. Ribelles N, Perez-Villa L, Jerez JM, et al. Pattern of recurrence of early breast cancer is different according to intrinsic subtype and proliferation index. Breast Cancer Res. 2013; 15(5): R98, doi: 10.1186/bcr3559, indexed in Pubmed: 24148581

6. La Verde N, Biagioli E, Gerardi C, et al. Role of patient and tumor characteristics in sentinel lymph node metastasis in patients with luminal early breast cancer: an observational study. Springerplus. 2016; 5: 114, doi: 10.1186/s40064-016-1720-9, indexed in Pubmed: 26885467.

7. Ding J, Jiang Li, Wu W. Predictive Value of Clinicopathological Characteristics for Sentinel Lymph Node Metastasis in Early Breast Cancer. Med Sci Monit. 2017; 23: 4102-4108, doi: 10.12659/msm.902795, indexed in Pubmed: 28839123.

8. Liu Z, Sahli Z, Wang Y, et al. Young age at diagnosis is associated with worse prognosis in the Luminal A breast cancer subtype: a retrospective institutional cohort study. Breast Cancer Res Treat. 2018; 172(3): 689702, doi: 10.1007/s10549-018-4950-4, indexed in Pubmed: 30225619.

9. Lian W, Fu F, Lin Y, et al. The Impact of Young Age for Prognosis by Subtype in Women with Early Breast Cancer. Sci Rep. 2017; 7(1): 11625 , doi: 10.1038/s41598-017-10414-x, indexed in Pubmed: 28912475.

10. Gooch J, King TA, Eaton A, et al. The extent of extracapsular extension may influence the need for axillary lymph node dissection in patients with T1-T2 breast cancer. Ann Surg Oncol. 2014; 21(9): 2897-2903, doi: 10.1245/s10434-014-3752-0, indexed in Pubmed: 24777858.

11. Chae AW, Vandewalker KM, Li YJ, et al. Quantitation of sentinel node metastatic burden and Her-2/neu over-expression accurately predicts residual axillary nodal involvement and extranodal disease in breast cancer. Eur J Surg Oncol. 2013; 39(6): 627-633, doi: 10.1016/j. ejso.2013.02.017, indexed in Pubmed: 23523315.

12. Cardoso F, Kyriakides $S$, Ohno $S$, et al. ESMO Guidelines Committee. Electronic address: clinicalguidelines@esmo.org. Early breast cancer: ESMO Clinical Practice Guidelines for diagnosis, treatment and follow-upt. Ann Oncol. 2019; 30(8): 1194-1220, doi: 10.1093/annonc/mdz173, indexed in Pubmed: 31161190.

13. Lebert JM, Lester R, Powell $\mathrm{E}$, et al. Advances in the systemic treatment of triple-negative breast cancer. Curr Oncol. 2018; 25(Suppl 1): S142-S150, doi: 10.3747/co.25.3954, indexed in Pubmed: 29910657.

14. Dawson SJ, Provenzano E, Caldas C. Triple negative breast cancers: clinical and prognostic implications. Eur J Cancer. 2009; 45 Suppl 1:27-40, doi: 10.1016/S0959-8049(09)70013-9, indexed in Pubmed: 19775602.

15. Gangi A, Mirocha J, Leong T, et al. Triple-negative breast cancer is not associated with increased likelihood of nodal metastases. Ann Surg Oncol. 2014; 21(13): 4098-4103, doi: 10.1245/s10434-014-3989-7, indexed in Pubmed: 25155393.

16. Pilewskie $M$, Morrow M. Axillary Nodal Management Following Neoadjuvant Chemotherapy: A Review. JAMA Oncol. 2017; 3(4): 549-555, doi: 10.1001/jamaoncol.2016.4163, indexed in Pubmed: 27918753.

17. Kędzierawski P, Bocian A, Radowicz-Chil A. Factors influencing the presence of metastases in non-sentinel nodes in breast cancer patients with a positive sentinel node. Med Sci. 2019; 7(9): 113-119.
18. Goyal A, Douglas-Jones A, Newcombe RG, et al. ALMANAC Trialists Group. Predictors of non-sentinel lymph node metastasis in breast cancer patients. Eur J Cancer. 2004; 40(11): 1731-1737, doi: 10.1016/j. ejca.2004.04.006, indexed in Pubmed: 15251163.

19. Fujii T, Yanagita Y, Fujisawa T, et al. Implication of extracapsular invasion of sentinel lymph nodes in breast cancer: prediction of nonsentinel lymph node metastasis. World J Surg. 2010; 34(3): 544-548, doi: 10.1007/s00268-009-0389-4, indexed in Pubmed: 20066412.

20. Gorgulu S, Can MF, Yagci G, et al. Extracapsular extension is associated with increased ratio of metastatic to examined lymph nodes in axillary node-positive breast cancer. Clin Breast Cancer. 2007; 7(10): 796-800, doi: 10.3816/CBC.2007.n.042, indexed in Pubmed: 18021482.

21. Meretoja TJ, Audisio RA, Heikkilä PS, et al. International multicenter tool to predict the risk of four or more tumor-positive axillary lymph nodes in breast cancer patients with sentinel node macrometastases. Breast Cancer Res Treat. 2013; 138(3): 817-827, doi: 10.1007/s10549013-2468-3, indexed in Pubmed: 23558360.

22. Palamba HW, Rombouts MC, Ruers TJ, et al. Extranodal extension of axillary metastasis of invasive breast carcinoma as a possible predictor for the total number of positive lymph nodes. Eur J Surg Oncol. 2001;27(8): 719-722, doi: 10.1053/ejso.2001.1173, indexed in Pubmed: 11735167.

23. Vane MLG, Willemsen MA, van Roozendaal LM, et al. Extracapsular extension in the positive sentinel lymph node: a marker of poor prognosis in CT1-2N0 breast cancer patients? Breast Cancer Res Treat. 2019; 174(3): 711-718, doi: 10.1007/s10549-018-05074-y, indexed in Pubmed: 30610488.

24. Schwentner L, Dayan D, Wöckel A, et al. Is extracapsular nodal extension in sentinel nodes a predictor for nonsentinel metastasis and is there an impact on survival parameters?-A retrospective single center cohort study with 324 patients. Breast J. 2018; 24(4): 480-486, doi: 10.1111/ tbj.12983, indexed in Pubmed: 29265572.

25. Nottegar A, Veronese N, Senthil M, et al. Extra-nodal extension of sentinel lymph node metastasis is a marker of poor prognosis in breast cancer patients: A systematic review and an exploratory meta-analysis. Eur J Surg Oncol. 2016; 42(7): 919-925, doi: 10.1016/j.ejso.2016.02.259, indexed in Pubmed: 27005805.

26. Veronese N, Nottegar A, Pea A, et al. Prognostic impact and implications of extracapsular lymph node involvement in colorectal cancer: a systematic review with meta-analysis. Ann Oncol. 2016; 27(1): 42-48, doi: 10.1093/annonc/mdv494, indexed in Pubmed: 26483050.

27. Luchini C, Veronese N, Pea A, et al. Extranodal extension in N1-adenocarcinoma of the pancreas and papilla of Vater. Eur J Gastroenterol Hepatol. 2016; 28(2): 205-209, doi: 10.1097/meg.0000000000000520.

28. Veronese N, Luchini C, Nottegar A, et al. Prognostic impact of extra-nodal extension in thyroid cancer: A meta-analysis. J Surg Oncol. 2015; 112(8): 828-833, doi: 10.1002/jso.24070, indexed in Pubmed: 26493240.

29. Flaming ID, Cooper JS, Henson DE. et al. (ed.). AJCC Cancer Staging Manual 5th edition. Lippincott Raven Publishers, Philadelphia 1997.

30. Drinka E, Allen P, McBride A, et al. Metastatic Tumor Volume and Extranodal Tumor Extension: Clinical Significance in Patients With Stage II Breast Cancer. Arch Pathol Lab Med. 2015; 139(10): 1288-1294, doi: 10.5858/arpa.2014-0375-OA, indexed in Pubmed: 25768237.

31. Choi AH, Surrusco M, Rodriguez $S$, et al. Extranodal extension on sentinel lymph node dissection: why should we treat it differently? Am Surg. 2014; 80(10): 932-935, indexed in Pubmed: 25264632.

32. Shigematsu $H$, Taguchi $K$, Koui $H$, et al. Clinical Significance of Extracapsular Invasion at Sentinel Lymph Nodes in Breast Cancer Patients with Sentinel Lymph Node Involvement. Ann Surg Oncol. 2015; 22(7): 2365-2371, doi: 10.1245/s10434-014-4269-2, indexed in Pubmed: 25476029.

33. Choi AH, Blount S, Perez MN, et al. Size of Extranodal Extension on Sentinel Lymph Node Dissection in the American College of Surgeons Oncology Group Z0011 Trial Era. JAMA Surg. 2015; 150(12): 1141-1148, doi: 10.1001/jamasurg.2015.1687, indexed in Pubmed: 26331347.

34. Barrio AV, Downs-Canner S, Edelweiss M, et al. Microscopic Extracapsular Extension in Sentinel Lymph Nodes Does Not Mandate Axillary Dissection in Z0011-Eligible Patients. Ann Surg Oncol. 2020; 27(5): 1617-1624, doi: 10.1245/s10434-019-08104-1, indexed in Pubmed: 31820212.

35. Kanyılmaz G, Findık S, Yavuz BB, et al. The Significance of Extent of Extracapsular Extension in Patients with T1-2 and N1 Breast Cancer. Eur J Breast Health. 2018; 14(4): 218-224, doi: 10.5152/ejbh.2018.4038, indexed in Pubmed: 30288496. 